\title{
Do not throw that sternal saw away yet...
}

\author{
George Tolis, Jr, MD, and Gus J. Vlahakes, MD
}

\footnotetext{
From the Division of Cardiac Surgery, Massachusetts General Hospital and Harvard Medical School, Boston, Mass.

Disclosures: Authors have nothing to disclose with regard to commercial support.

Received for publication Sept 28, 2017; accepted for publication Oct 9, 2017; available ahead of print Nov 9 , 2017.

Address for reprints: Gus J. Vlahakes, MD, Division of Cardiac Surgery, Massachusetts General Hospital, 55 Fruit

St, COX630, Boston, MA 02114 (E-mail: vlahakes.gus@mgh.harvard.edu).

J Thorac Cardiovasc Surg 2018;155:937

$0022-5223 / \$ 36.00$

Copyright (c) 2017 by The American Association for Thoracic Surgery

https://doi.org/10.1016/j.jtcvs.2017.10.005
}

In their single-surgeon study in this issue of the Journal, Lamelas and colleagues ${ }^{1}$ describe their experience with the right minithoracotomy for treating aortic valve disease with or without other concomitant pathologies. Their "intent to treat" the diseased aortic valve with this incision was strictly adhered to during a 6-year period and in more than 1000 cases. The outcomes reported are exceptional. Lamelas and colleagues ${ }^{1}$ are to be congratulated for their outstanding delivery of patient care and their bold vision to advance our field to new frontiers.

Dr Lamelas has clearly mastered this technique and has produced outcomes that rival, if not exceed, the standards set by other institutions. One can only wonder whether these outcomes, especially the ones in the older age group, would be even better if Dr Lamelas decided to perform the procedure in the "over 80 " group with a standard median sternotomy. In a recent study, presented at the 2017 American Association for Thoracic Surgery annual meeting in Boston, we compared outcomes of cases done by sternotomy entirely ("skin-to-skin") by residents versus cases done entirely by a single attending. ${ }^{2}$ The attending-only cardiopulmonary bypass time for isolated aortic valve replacement was 59 minutes (interquartile range, 52-60 minutes), and the aortic crossclamp time was 47 minutes (interquartile range, 40-49 minutes). ${ }^{2}$ In the series of Lamelas and colleagues, ${ }^{1}$ the mean cardiopulmonary bypass times and crossclamp times were 101 and 76 minutes, respectively. Are the deleterious effects of a $75 \%$ increase in perfusion and ischemia times offset by the location of the incision? Prolonging an operation in a vulnerable group of patients to achieve minimal access may concern some surgeons. This question can only be answered through a prospective, randomized study.

Lamelas and colleagues ${ }^{1}$ are also to be commended for their efforts to teach other surgeons how to perform these operations safely and how to build a team dedicated to minimally invasive surgery. What needs to be stressed, however, is that the most important prerequisite to "sit" for the minimally invasive course is to have mastered the standard sternotomy open technique with a standard prosthesis and hand tying of all knots. It is for this very reason that these hypertrophy.

\section{References}

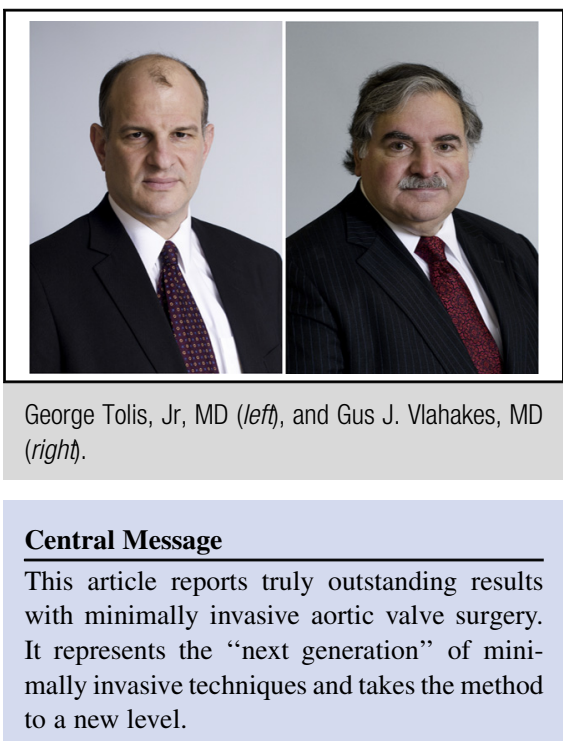

See Article page 926.

techniques have not been widely adapted by many teaching institutions responsible for delivering outstanding patient care while training the next generation of cardiac surgeons.

We urge caution when planning myocardial protection. The statement that "del Nido [cardioplegia] allows for at least 90 minutes of safe myocardial protection" is a concern. Although not having to interrupt the operation to deliver cardioplegia may be attractive in minimal access surgery, considerable differences of opinion and outcomes experience exist with del Nido cardioplegia for adult cardiac surgery, particularly in the presence of ventricular

In the 1970s, cardiac surgeons had to learn microvascular techniques to stay current, because coronary surgery worked and was reproducible. Minithoracotomy aortic valve replacement clearly works in this setting for Dr Lamelas and his patients, but if it does not prove to be reproducible without a prohibitive learning curve among his institutional colleagues - to start with-or among most surgeons in the community, it is unlikely to get past the stage of impressive articles and slide presentations.

1. Lamelas J, Mawad M, Williams R, Weiss UK, Zhang Q, LaPietra A. Isolated and concomitant minimally invasive minithoracotomy aortic valve surgery. J Thorac Cardiovasc Surg. 2018;155:926-36.e2.

2. Tolis G Jr, Spencer PJ, Bloom J, Melnitchouk S, D'Alessandro DA, Villavicencio MA, et al. Teaching operative cardiac surgery in the era of increasing patient complexity: can it still be done? Presented at: 97th Annual Meeting of The American Association for Thoracic Surgery; April 29-May 3, 2017; Boston, Mass. 